\title{
Early vascular healing of ultra-thin strut polymer- free sirolimus-eluting stents in acute coronary syndrome: USUI-ACS study
}

\section{Yutaka Matsuhiro}

Osaka Rosai Hospital: Osaka Rosai Byoin

\section{Yasuyuki Egami}

Osaka Rosai Hospital: Osaka Rosai Byoin

\section{Naotaka Okamoto}

Osaka Rosai Hospital: Osaka Rosai Byoin

\section{Masaya Kusuda}

Osaka Rosai Hospital: Osaka Rosai Byoin

\section{Takashige Sakio}

Osaka Rosai Hospital: Osaka Rosai Byoin

Hiroaki Nohara

Osaka Rosai Hospital: Osaka Rosai Byoin

Hiroki Sugae

Osaka Rosai Hospital: Osaka Rosai Byoin

Shodai Kawanami

Osaka Rosai Hospital: Osaka Rosai Byoin

Akito Kawamura

Osaka Rosai Hospital: Osaka Rosai Byoin

Kohei Ukita

Osaka Rosai Hospital: Osaka Rosai Byoin Hitoshi Nakamura

Osaka Rosai Hospital: Osaka Rosai Byoin

Koji Yasumoto

Osaka Rosai Hospital: Osaka Rosai Byoin

\section{Masaki Tsuda}

Osaka Rosai Hospital: Osaka Rosai Byoin

Yasuharu Lee Matsunaga

Osaka Rosai Hospital: Osaka Rosai Byoin

\section{Masamichi Yano}

Osaka Rosai Hospital: Osaka Rosai Byoin

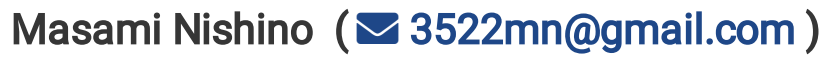


Osaka Rosai Hospital https://orcid.org/0000-0003-0309-7023

Jun Tanouchi

Osaka Rosai Hospital: Osaka Rosai Byoin

\section{Research Article}

Keywords: vascular healing, ultra-thin strut, polymer-free, optical coherence tomography

Posted Date: November 15th, 2021

DOI: https://doi.org/10.21203/rs.3.rs-1060996/v1

License: (c) (i) This work is licensed under a Creative Commons Attribution 4.0 International License. Read Full License 


\section{Abstract}

\section{Purpose:}

Ultra-thin strut polymer-free sirolimus eluting stent (UPF-SES) have two novel characteristics, ultra-thin strut and polymer-free coating, which have the potential to achieve early re-endotherialization. However, a little is known whether early vascular healing of UPF-SES can be achieved in patients with acute coronary syndrome (ACS).

The aim of this study was to evaluate the vascular healing after an implantation of UPF-SES in patients with ACS using optical coherence tomography (OCT) at 3 months after the stent implantation.

\section{Methods:}

From September 2020 and January 2021, a total of 31 consecutive patients presenting with ACS who underwent OCT examinations at the initial percutaneous coronary intervention (PCI) and 3-month followup were enrolled in the USUI-ACS study. The endpoints of this study were neointimal strut coverage, malapposition, and mean neointimal hyperplasia $(\mathrm{NIH})$ thickness at 3-month follow-up.

\section{Results:}

Over a mean follow-up of 91 days after the initial PCl, the follow-up OCT was examined. The median percentage of covered struts was $98.4 \%$ and malapposed struts $0 \%$, and the mean $\mathrm{NIH}$ thickness was $60 \mu \mathrm{m}$.

\section{Conclusions:}

UPF-SES exhibited an excellent early vascular healing at 3-months in patients with ACS.

\section{Introduction}

As compared to bare metal stents, first generation drug-eluting stents (DESs) have dramatically reduced the incidence of restenosis and target lesion revascularization by inhibiting neointimal hyperplasia.[1] However, there remain concern about the increasing risk of late stent thrombosis related to incomplete endothelialization and delayed healing.[2-4] Therefore, new generation DESs have been designed to overcome these limitations by using different antiproliferative drugs and release kinetics, thinner and improved stent struts, and the development of biocompatible, bioabsorbable polymer coatings or a polymer-free technology. Ultra-thin strut polymer-free sirolimus eluting stent (UPF-SES) (Coroflex ISAR NEO; B Braun Melsungen AG, Melsungen, Germany) is a newly developed DES that consist of ultra-thin struts ( $55 \mu \mathrm{m}$ for less than $3 \mathrm{~mm}$ stents and $65 \mu \mathrm{m}$ for $3.5-4.0 \mathrm{~mm}$ stents) with a dual drug coating of probucol and sirolimus without a polymer. As a hypothesis, ultra-thin struts cause less vessel injury than thicker struts, and a non-polymer coating avoids local arterial hypersensitivity and chronic inflammatory reactions. Therefore, UPF-SES can achieve early vascular healing after stent implantation. Actually, 
FRIENDLY OCT trial compared UPF-SES (Coroflex ISAR; B. Braun Melsungen AG, Melsungen, Germany), which consist of ultra-thin struts $(50 \mu \mathrm{m}$ for less than $2.5 \mathrm{~mm}$ and $60 \mu \mathrm{m}$ for more than $2.75 \mathrm{~mm})$ and a dual drug coating (probucol and sirolimus) without a polymer, with thin strut bioabsorbable polymer coating SES (BP-SES) (Ultimaster; Termo Corporation, Tokyo, Japan) at the 3-month follow-up optical coherence tomography (OCT).[5] The study demonstrated that UPF-SES had earlier and excellent vascular healing than BP-SES at 3 months. However, the major limitations of the study were exclusion of STEMI patients whose vascular healing could be delayed, and inclusion of high proportion of non-acute coronary syndrome (ACS) patients (44\%).[5] Therefore, a little is known whether early vascular healing of UPF-SES can be achieved even in ACS.

We conducted a prospective observational study to evaluate whether early vascular healing of UPF-SES can be achieved in patients with ACS using 3-month follow-up OCT examination.

\section{Methods}

\section{Patient Population}

We prospectively enrolled consecutive patients who underwent percutaneous coronary intervention (PCI) in our institution from September 2020 to January 2021. All the patients were registered in the early

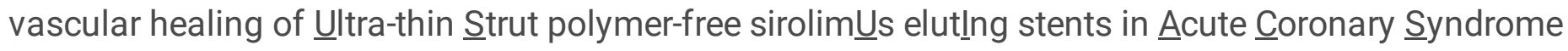
(USUI-ACS) registry. The inclusion criteria were as follows: 1) patients presenting with ACS (ST-segment elevation myocardial infarction [STEMI], non-ST-segment elevation myocardial infarction [NSTEMI], and unstable angina [UA]); 2) de novo lesion with >50\% diameter stenosis; 3 ) patients who underwent OCT examination during the initial $\mathrm{PCl}$; and 4) patients who agreed to follow-up angiographic and OCT examination at 3-month. The exclusion criteria were as follows: 1) a left main lesion or coronary bypass graft lesion; 2) in-stent restenosis; and 3) chronic kidney disease defined as a serum creatinine level > $2.0 \mathrm{mg} / \mathrm{dl}$ or maintenance hemodialysis. A loading dose of aspirin (81-200mg) and prasugrel (20mg) (the standard loading dose in Japan) was administered before the PCI. Dual antiplatelet therapy (DAPT) was recommended in accordance with the Japanese Circulation Society guidelines.[6] Written informed consent to participation was obtained from all patients in accordance with the Declaration of Helsinki, and the protocol was approved by the Osaka Rosai Hospital ethics committees. It was registered under the Japanese UMIN Clinical Trial Registration (UMIN 000042271).

\section{Procedural management}

$\mathrm{PCl}$ was performed according to standard techniques. The direct stenting, thrombectomy, pre-dilatation, and post dilatation were left to each operator's discretion, and the operator referred to the OCT findings to determine the strategy.

\section{Study Endpoints}


The study primary endpoint was the percentage of covered struts at the 3-month follow-up. Secondary endpoints were the other OCT findings at the 3-month follow-up including the percentage of malapposed struts and mean neointimal hyperplasia $(\mathrm{NIH})$ thickness.

\section{OCT Image Acquisition}

OCT images were acquired with a frequency domain OCT system (Abbott Vascular, Santa Clara, CA, USA) after the administration of intracoronary nitroglycerin. A conventional angioplasty guidewire (0.014-inch) was advanced distal to the region of interest, and then the OCT imaging catheter (Dragonfly OpStar, Abbott Vascular, Santa Clara, CA, USA) was advanced over the guidewire beyond the region of interest. During the imaging acquisition, blood was displaced by an injection of contrast media. The images were calibrated by an automated adjustment of the Z-offset and the automated pullback was set at 18 or $36 \mathrm{~mm} / \mathrm{s}$.

\section{OCT Image Analysis}

We performed quantitative and qualitative OCT analyses using dedicated software (Off-line Review Workstation, version E.0.2, Abbott Vascular, Santa Clara, CA, USA). We previously published the details of the OCT analysis.[7,8] All variables were analyzed at lesion level. In brief, the cross-sectional OCT images were analyzed at 1-mm intervals within the entire target segment of the pre-procedural, post-procedural, and 3-month follow-up OCT data. Struts were classified as uncovered if any part of the strut was visibly exposed to the lumen and as covered if a layer of tissue was visible over all the reflecting surfaces. A malapposed strut was defined as a distance between the center of the strut blooming into the luminal contour of the arterial wall of $>55 \mu \mathrm{m}$ for less than $3 \mathrm{~mm}$ stents and $>65 \mu \mathrm{m}$ for $3.5-4.0 \mathrm{~mm}$ stents. The $\mathrm{NIH}$ thickness was defined as the distance between the endoluminal surface of the strut reflection and the lumen contour. The inter-observer reproducibility of the OCT image analysis in our institution were shown in a previous article.[7]

\section{Statistical Analysis}

No sample size calculation was performed due to the absence of previous data. Categorical variables are stated as numbers (percentages) and compared using a Pearson's chi-squared test. Continuous variables are stated as the mean \pm standard deviation or median (interquartile range) and compared using a Student's $t$-test and the Mann-Whitney U-test, based on the distribution. A p value $<0.05$ was considered significant. The statistical analysis was performed using the $\mathrm{R}$ programming language and environment version 3.6.1.

\section{Results}

\section{Study Population}


Figure 1 shows the study flow chart. From September 2020 and January 2021, a total of 31 consecutive patients were enrolled in the present study. 25 ineligible patients were treated with intravascular

ultrasound mainly due to chronic kidney disease, ostial lesion and lesion tortuosity. 3 patients were lost to follow-up due to COVID-19 pandemic, and one patient was due to the progression of cancer and the other patient was due to the progression of interstitial pneumonia. There was no patient who had any cardiac events during the 3 months.

\section{Patient, Lesion, And Procedural Characteristics}

The baseline patient, lesion, and procedural characteristics are summarized in Table 1. The proportion of STEMIs was $65 \%$, NSTEMI $23 \%$, and UA $13 \%$. The median stent size and length were $3.00 \mathrm{~mm}$ and $28 \mathrm{~mm}$, respectively. All patients had DAPT for 3 months. 
Table 1

Baseline patient, lesion and procedural characteristics.

$\mathrm{N}=31$

Patient characteristics

Age, year

$71 \pm 11$

Height, $\mathrm{cm}$

$162 \pm 9$

Weight, $\mathrm{kg}$

$65 \pm 14$

Body mass index, $\mathrm{kg} / \mathrm{m}^{2}$

$25 \pm 4$

Male, $n$

$21(68 \%)$

Diabetes mellitus, $n$

$8(26 \%)$

Hypertension, $\mathrm{n}$

$22(71 \%)$

Dyslipidemia, $\mathrm{n}$

$25(81 \%)$

Current Smoker, $\mathrm{n}$

$6(19 \%)$

eGFR $<60 \mathrm{ml} / \mathrm{min} / 1.73 \mathrm{~m}^{2}, \mathrm{n}$

$13(42 \%)$

Prior myocardial infarction, $\mathrm{n}$

$1(3 \%)$

Prior PCl, $\mathrm{n}$

$3(10 \%)$

Lesion characteristics

Location

$L A D, n$

13 (42\%)

LCX, n

$5(16 \%)$

$\mathrm{RCA}, \mathrm{n}$

$13(42 \%)$

Presentation

STEMI, $\mathrm{n}$

$20(65 \%)$

NSTEMI, $\mathrm{n}$

7 (23\%)

UA, $n$

$4(13 \%)$

Lesion type

Values are the mean \pm standard deviation, number (\%), or median [interquartile range].

eGFR = estimated glomerular filtration rate; $L A D=$ left anterior descending; $L C X$ = left circumflex; $L M T$ = left main trunk; NSTEMI = non-ST elevation myocardial infarction; RCA = right coronary artery; $\mathrm{PCl}=$ percutaneous coronary intervention; STEMI = ST elevation myocardial infarction; $\mathrm{UA}=$ unstable angina. 


\begin{tabular}{|c|c|}
\hline & $\mathrm{N}=31$ \\
\hline A/B1, n & $13(42 \%)$ \\
\hline$B 2 / C, n$ & $18(58 \%)$ \\
\hline \multicolumn{2}{|l|}{ Procedural characteristics } \\
\hline Stent size, mm & $3.00[2.94,3.50]$ \\
\hline Stent length, mm & $28[22,38]$ \\
\hline Pre dilatation, $\mathrm{n}$ & $26(84 \%)$ \\
\hline Pre dilatation balloon size, $\mathrm{mm}$ & $2.50[2.00,3.19]$ \\
\hline Post dilatation, $n$ & $16(52 \%)$ \\
\hline Post dilatation balloon size, $\mathrm{mm}$ & $3.25[3.00,3.50]$ \\
\hline Post dilatation balloon pressure, atm & $20[20,22]$ \\
\hline Thrombectomy, $\mathrm{n}$ & $16(52 \%)$ \\
\hline \multicolumn{2}{|c|}{ Values are the mean \pm standard deviation, number (\%), or median [interquartile range]. } \\
\hline \multicolumn{2}{|c|}{$\begin{array}{l}\text { eGFR = estimated glomerular filtration rate; } \mathrm{LAD}=\text { left anterior descending; } \mathrm{LCX}=\text { left circumflex; } \mathrm{LMT} \\
=\text { left main trunk; NSTEMI = non-ST elevation myocardial infarction; RCA = right coronary artery; PCI = } \\
\text { percutaneous coronary intervention; STEMI = ST elevation myocardial infarction; } \mathrm{UA}=\text { unstable } \\
\text { angina. }\end{array}$} \\
\hline
\end{tabular}

\section{Oct Findings At Pre And Post Procedure}

Only one pre-procedure OCT pull-back image was excluded because of a poor image quality. All the other OCT pull-back images were analyzed. Table 2 shows the pre-procedural and post-procedural OCT findings. White or red thrombus was observed in $63 \%$ and plaque rupture in $67 \%$. The minimum stent area was $5.66 \mathrm{~mm}^{2}$. The percentage of malapposed struts was $2.3 \%$ and proportion of irregular protrusion $61 \%$. 
Table 2

Pre-procedural and post-procedural OCT findings.

\begin{tabular}{|c|c|}
\hline Pre-procedural OCT findings & $\mathrm{N}=30$ \\
\hline Distal reference lumen area, $\mathrm{mm}^{2}$ & $6.54[4.04,7.83]$ \\
\hline Distal reference mean diameter, $\mathrm{mm}$ & $2.88[2.26,3.15]$ \\
\hline Proximal reference lumen area, $\mathrm{mm}^{2}$ & $8.32[6.60,11.30]$ \\
\hline Proximal reference mean diameter, $\mathrm{mm}$ & $3.23[2.87,3.79]$ \\
\hline Mean reference area, $\mathrm{mm}^{2}$ & $7.67[5.17,9.84]$ \\
\hline Minimum lumen area, $\mathrm{mm}^{2}$ & $1.04[0.76,1.25]$ \\
\hline Minimum lumen diameter, $\mathrm{mm}$ & $1.12[0.98,1.25]$ \\
\hline \multicolumn{2}{|l|}{ Morphology } \\
\hline Plaque rupture, $\mathrm{n}$ & $20(67 \%)$ \\
\hline Plaque erosion, $\mathrm{n}$ & $2(7 \%)$ \\
\hline Calcified nodule, $\mathrm{n}$ & $1(3 \%)$ \\
\hline White or red Thrombus, $\mathrm{n}$ & $19(63 \%)$ \\
\hline Lipid rich plaque, $n$ & $28(93 \%)$ \\
\hline Thin cap fibroatheroma $\leq 65 \mu \mathrm{m}, \mathrm{n}$ & $20(71 \%)$ \\
\hline Minimum fibrous cap thickness, $\mu \mathrm{m}$ & $50[40,73]$ \\
\hline Maximum lipid arc, degree & $343[246,360]$ \\
\hline Mean lipid arc, degree & $165[127,193]$ \\
\hline Total lipid length, mm & $11[6,18]$ \\
\hline Calcified plaque, $\mathrm{n}$ & $17(57 \%)$ \\
\hline Maximum calcium thickness, $\mu \mathrm{m}$ & $880[630,1000]$ \\
\hline Maximum calcium arc, degree & $151[95,208]$ \\
\hline Mean calcium arc, degree & $78[65,100]$ \\
\hline Post-procedural OCT findings & $N=31$ \\
\hline Minimum lumen area, $\mathrm{mm}^{2}$ & $5.46[4.08,7.04]$ \\
\hline Minimum stent area, $\mathrm{mm}^{2}$ & $5.66[4.20,7.21]$ \\
\hline Minimum expansion index & $76[70,89]$ \\
\hline
\end{tabular}




\begin{tabular}{|ll|}
\hline Pre-procedural OCT findings & $\mathrm{N}=\mathbf{3 0}$ \\
\hline Stent expansion index, \% & $72[66,83]$ \\
\hline Malapposed struts, \% & $2.3[0.9,5.4]$ \\
\hline Edge dissection, $\mathrm{n}$ & 0 \\
\hline Protrusion & \\
\hline Smooth, $\mathrm{n}$ & $30(97 \%)$ \\
\hline Disrupted, $\mathrm{n}$ & $15(48 \%)$ \\
\hline Irregular, $\mathrm{n}$ & $19(61 \%)$ \\
\hline
\end{tabular}

\section{Three-month Follow-up Oct Findings}

The mean follow-up OCT analysis was performed 91 days after the initial PCI. The follow-up OCT findings are presented in Table 3. The percentage of covered struts was $98.4 \%$ and malapposed struts $0 \%$, and the mean $\mathrm{NIH}$ thickness was $60 \mu \mathrm{m}$. Figure 2 shows the individual serial changes in the percentage of malapposed struts. The percentage of malapposed struts significantly decreased during the 3-month follow-up period $(p<0.01)$. No thrombus or irregular protrusion were observed at the 3-month follow-up. Figure 3 demonstrates the representative OCT images of the struts and neointimal coverage over 3-month.

Table 3

3-month follow-up OCT findings.

\begin{tabular}{|ll|}
\hline & $\mathrm{N}=31$ \\
\hline Covered struts, \% & $98.4[97.2,99.6]$ \\
\hline Malapposed struts, \% & $0.0[0.0,0.7]$ \\
\hline Mean NIH thickness, $\mu \mathrm{m}$ & $80[60,100]$ \\
\hline Mean lumen area, $\mathrm{mm}^{2}$ & $6.96[5.25,8.68]$ \\
\hline Minimum lumen area, $\mathrm{mm}^{2}$ & $5.31[3.87,6.74]$ \\
\hline Mean stent area, mm ${ }^{2}$ & $7.42[5.65,9.00]$ \\
\hline Minimum stent area, mm² & $5.67[4.14,6.97]$ \\
\hline In-stent thrombus, $\mathrm{n}$ & 0 \\
\hline Irregular protrusion, $\mathrm{n}$ & 0 \\
\hline NIH = neointimal hyperplasia. & \\
\hline
\end{tabular}

Page $10 / 18$ 


\section{Discussion}

The present OCT study demonstrated excellent strut coverage and apposition of the UPF-SES at 3-month follow-up in patients with ACS.

\section{Early Vascular Healing Of Upf-ses}

The recent OCT analysis of UPF-SES, FRIENDLY OCT trial, showed that the percentage of covered struts at 3 months was significantly higher in UPF-SES than BP-SES ( $96.89 \%$ vs. $94.65 \% ; \mathrm{P}<0.001$, respectively) in patients with non-ACS, NSTEMI and UA.[5] On the other hand, the present study showed the strut coverage of UPF-SES at 3 months in patients ACS including STEMI, NSTEMI and UA. Concerning the pathology, it has been reported that vessel healing of DESs in patients with ACS is substantially delayed as compared to that in those with stable angina.[9] Actually, MECHANISM-ULTIMASTER study, the study evaluated the serial vascular healing of BP-SES, showed that the percentage of covered struts were significantly lower in STEMI patients than in non-ACS patients.[10] Our data demonstrated that the strut coverage of UPF-SES in ACS patients were comparable to that of FRIENDLY OCT trial ( $98.4 \%$ vs. $96.89 \%$, respectively) even though our study population had higher risk of delayed healing than the population of FRIENDLY OCT trial. This result can be related to the unique characteristics of UPF-SES.

\section{Unique Characteristics Of Upf-ses}

UPF-SES has two unique characteristics, ultra-thin strut and non-polymer coating. In the bare metal stent era, the ISAR-STEREO trial and ISAR-STEREO-2 trial revealed that ultra-thin struts are associated with more favorable clinical results than that of thick struts due to less vessel injury and inflammation.[11,12] Another article has shown that low endothelial shear stress downstream of the thick strut promotes stent thrombogenicity and retards re-endothelialization.[13] On the other hand, durable polymer can cause a chronic inflammatory reaction and lead to delayed re-endothelialization.[14,15] To overcome this problem, bioabsorbable polymer coatings have been developed and added to new generation DESs. Actually, several OCT studies have demonstrated that bioabsorbable polymer coating have an earlier vascular healing than durable polymer coating. $[7,16]$ As a hypothesis, polymer-free stents can be free from polymer-related inflammation just after stent implantation and may promote earlier re-endothelialization than bioabsorbable polymer DESs. In summary, both ultra-thin strut and non-polymer coating can achieve early vascular healing.

\section{Clinical Implications}

ACS is a cornerstone of $\mathrm{PCl}$ even with the development of DESs. A high rate of target lesion failure including stent thrombosis occurs in ACS patients and stent thrombosis is occasionally relates to high mortality rate.[17-20] From the PARIS registry, ACS is an independent predictor of coronary thrombotic 
events.[21] The ACC/AHA and ESC guidelines demonstrated that long DAPT is recommended for patients with ACS.[22,23] On the other hand, long DAPT has been reported to be associated with increased major bleeding and mortality.[24] Previous OCT study has shown that the presence of uncovered and malapposed struts are the major causes of stent thrombosis.[25] Therefore, an alternative stent design, in which early strut coverage is observed, is necessary for ACS to achieve a safe and early discontinuation of DAPT and UPF-SES may be one of the options for patients with ACS whom we would like to discontinue DAPT in early terms.

\section{Limitations}

The major limitations of the present study were single-arm design and very small sample size. We did not show any further clinical benefit of UPF-SES over other recent DESs in the present study. There is also insufficient clinical evidence for UPF-SES as compared to the other recent DESs in patients with ACS. However, to the best of our knowledge, the present study was the first to show the early vascular healing of UPF-SES in patients with ACS including STEMI, and we hope our result leads to new and large-scale randomized clinical trials of UPF-SES in patients with ACS.

\section{Conclusions}

The results of the USUI-ACS study demonstrated that ultra-thin strut polymer-free sirolimus eluting stents had excellent vascular healing at the 3-month follow-up in patients with ACS.

\section{Declarations}

Acknowledgements The authors thank Mr. John Martin for his linguistic assistance with this manuscript.

Funding We have no funding.

\section{Compliance with ethical standards}

Conflict of interest statement We have no conflict of interest.

Research involving human participants and/or animals All procedures performed in this study involving human participants were in accordance with the ethical standards of the institutional research committee and the 1964 Helsinki Declaration and its later amendments or comparable ethical standards.

Informed consent Written informed consent was obtained from all participating patients and the protocol was approved by Osaka Rosai Hospital ethics committees.

\section{References}

1. Moses JW, Leon MB, Popma JJ, Fitzgerald PJ, Holmes DR, O'Shaughnessy C, Caputo RP, Kereiakes DJ, Williams DO, Teirstein PS, Jaeger JL, Kuntz RE (2003) Sirolimus-eluting stents versus standard stents in 
patients with stenosis in a native coronary artery. N Engl J Med 349 (14):1315-1323. doi:10.1056/NEJMoa035071

2. Cook S, Wenaweser $P$, Togni M, Billinger M, Morger $C$, Seiler $C$, Vogel R, Hess $O$, Meier B, Windecker $S$ (2007) Incomplete stent apposition and very late stent thrombosis after drug-eluting stent implantation. Circulation 115 (18):2426-2434. doi:10.1161/circulationaha.106.658237

3. Stefanini GG, Holmes DR, Jr. (2013) Drug-eluting coronary-artery stents. N Engl J Med 368 (3):254-265. doi:10.1056/NEJMra1210816

4. Finn AV, Joner M, Nakazawa G, Kolodgie F, Newell J, John MC, Gold HK, Virmani R (2007) Pathological correlates of late drug-eluting stent thrombosis: strut coverage as a marker of endothelialization. Circulation 115 (18):2435-2441. doi:10.1161/circulationaha.107.693739

5. Otaegui I, Pérez de Prado A, Massotti M, López-Benito M, Sabaté M, Martí G, Bellera N, Serra B, García Del Blanco B, Ferreira González I (2020) Intrapatient Randomization to Study Strut Coverage in PolymerFree Versus Biodegradable-Polymer Sirolimus-Eluting Stent Implantations. JACC Cardiovasc Interv 13 (7):899-900. doi:10.1016/j.jcin.2019.11.020

6. Nakamura M, Kimura K, Kimura T, Ishihara M, Otsuka F, Kozuma K, Kosuge M, Shinke T, Nakagawa Y, Natsuaki M, Yasuda S, Akasaka T, Kohsaka S, Haze K, Hirayama A (2020) JCS 2020 Guideline Focused Update on Antithrombotic Therapy in Patients With Coronary Artery Disease. Circ J 84 (5):831-865. doi:10.1253/circj.CJ-19-1109

7. Matsuhiro Y, Nakamura D, Shutta R, Kawamura A, Nakamura H, Okamoto N, Matsunaga-Lee $Y$, Yano M, Egami Y, Sakata Y, Nishino M, Tanouchi J (2021) Difference of vascular healing between bioabsorbablepolymer and durable-polymer new generation drug-eluting stents: an optical coherence tomographic analysis. Int J Cardiovasc Imaging 37 (4):1131-1141. doi:10.1007/s10554-020-02094-y

8. Matsuhiro Y, Matsunaga-Lee Y, Nakamura D, Yano M, Yamato M, Egami Y, Shutta R, Sakata Y, Nishino M, Tanouchi J (2019) Characteristics of abnormal post-stent optical coherence tomography findings in hemodialysis patients. Catheter Cardiovasc Interv 94 (7):956-963. doi:10.1002/ccd.28188

9. Nakazawa G, Finn AV, Joner M, Ladich E, Kutys R, Mont EK, Gold HK, Burke AP, Kolodgie FD, Virmani R (2008) Delayed arterial healing and increased late stent thrombosis at culprit sites after drug-eluting stent placement for acute myocardial infarction patients: an autopsy study. Circulation 118 (11):1138-1145. doi:10.1161/circulationaha.107.762047

10. Itoh T, Otake H, Kimura T, Tsukiyama Y, Kikuchi T, Okubo M, Hayashi T, Okamura T, Kuramitsu S, Morita T, Sonoda S, Ishihara S, Kuriyama N, Isshiki T, Soeda T, Hibi K, Shinke T, Morino Y (2021) A serial optical frequency-domain imaging study of early and late vascular responses to bioresorbable-polymer sirolimus-eluting stents for the treatment of acute myocardial infarction and stable coronary artery 
disease patients: results of the MECHANISM-ULTIMASTER study. Cardiovasc Interv Ther. doi:10.1007/s12928-021-00777-4

11. Kastrati A, Mehilli J, Dirschinger J, Dotzer F, Schühlen H, Neumann FJ, Fleckenstein M, Pfafferott C, Seyfarth M, Schömig A (2001) Intracoronary stenting and angiographic results: strut thickness effect on restenosis outcome (ISAR-STEREO) trial. Circulation 103 (23):2816-2821. doi:10.1161/01.cir.103.23.2816

12. Pache J, Kastrati A, Mehilli J, Schühlen H, Dotzer F, Hausleiter J, Fleckenstein M, Neumann FJ, Sattelberger U, Schmitt C, Müller M, Dirschinger J, Schömig A (2003) Intracoronary stenting and angiographic results: strut thickness effect on restenosis outcome (ISAR-STEREO-2) trial. J Am Coll Cardiol 41 (8):1283-1288. doi:10.1016/s0735-1097(03)00119-0

13. Kolandaivelu K, Swaminathan R, Gibson WJ, Kolachalama VB, Nguyen-Ehrenreich KL, Giddings VL, Coleman L, Wong GK, Edelman ER (2011) Stent thrombogenicity early in high-risk interventional settings is driven by stent design and deployment and protected by polymer-drug coatings. Circulation 123 (13):1400-1409. doi:10.1161/circulationaha.110.003210

14. Joner M, Finn AV, Farb A, Mont EK, Kolodgie FD, Ladich E, Kutys R, Skorija K, Gold HK, Virmani R (2006) Pathology of drug-eluting stents in humans: delayed healing and late thrombotic risk. J Am Coll Cardiol 48 (1):193-202. doi:10.1016/j.jacc.2006.03.042

15. Virmani R, Guagliumi G, Farb A, Musumeci G, Grieco N, Motta T, Mihalcsik L, Tespili M, Valsecchi O, Kolodgie FD (2004) Localized hypersensitivity and late coronary thrombosis secondary to a sirolimuseluting stent: should we be cautious? Circulation 109 (6):701-705.

doi:10.1161/01.cir.0000116202.41966.d4

16. Shimoda M, Ando H, Naito K, Suzuki A, Sakurai S, Nakano Y, Kurita A, Waseda K, Takashima H, Murotani K, Uetani T, Amano T (2018) Early-Phase Vascular Healing of Bioabsorbable vs. Durable Polymer-Coated Everolimus-Eluting Stents in Patients With ST-Elevation Myocardial Infarction - 2-Week and 4-Month Analyses With Optical Coherence Tomography. Circ J 82 (10):2594-2601. doi:10.1253/circj.CJ-18-0230

17. Kukreja N, Onuma Y, Garcia-Garcia HM, Daemen J, van Domburg R, Serruys PW (2009) The risk of stent thrombosis in patients with acute coronary syndromes treated with bare-metal and drug-eluting stents. JACC Cardiovasc Interv 2 (6):534-541. doi:10.1016/j.jcin.2009.04.003

18. Krackhardt F, Kočka V, Waliszewski M, Toušek P, Janek B, Trenčan M, Krajči P, Lozano F, Roman KG, Otaegui I, Del Blanco BG, Del Olmo VV, Nofrerías EF, Wachowiak L, Heang TM, Ahn TH, Jeong MH, Jung BC, Han KR, Piot C, Sebagh L, Rischner J, Pansieri M, Leschke M (2020) Unrestricted use of polymer-free sirolimus eluting stents in routine clinical practice. Medicine (Baltimore) 99 (8):e19119.

doi:10.1097/md.0000000000019119 
19. Ananthakrishna R, Kristanto W, Liu L, Chan SP, Loh PH, Tay EL, Chan KH, Chan MY, Lee CH, Low AF, Tan HC, Loh JP (2018) Incidence and predictors of target lesion failure in a multiethnic Asian population receiving the SYNERGY coronary stent: A prospective all-comers registry. Catheter Cardiovasc Interv 92 (6):1097-1103. doi:10.1002/ccd.27577

20. Claessen BE, Henriques JP, Jaffer FA, Mehran R, Piek JJ, Dangas GD (2014) Stent thrombosis: a clinical perspective. JACC Cardiovasc Interv 7 (10):1081-1092. doi:10.1016/j.jcin.2014.05.016

21. Baber U, Mehran R, Giustino G, Cohen DJ, Henry TD, Sartori S, Ariti C, Litherland C, Dangas G, Gibson CM, Krucoff MW, Moliterno DJ, Kirtane AJ, Stone GW, Colombo A, Chieffo A, Kini AS, Witzenbichler B, Weisz G, Steg PG, Pocock S (2016) Coronary Thrombosis and Major Bleeding After PCI With Drug-Eluting Stents: Risk Scores From PARIS. J Am Coll Cardiol 67 (19):2224-2234. doi:10.1016/j.jacc.2016.02.064

22. Levine GN, Bates ER, Bittl JA, Brindis RG, Fihn SD, Fleisher LA, Granger CB, Lange RA, Mack MJ, Mauri L, Mehran R, Mukherjee D, Newby LK, O'Gara PT, Sabatine MS, Smith PK, Smith SC, Jr. (2016) 2016 ACC/AHA Guideline Focused Update on Duration of Dual Antiplatelet Therapy in Patients With Coronary Artery Disease: A Report of the American College of Cardiology/American Heart Association Task Force on Clinical Practice Guidelines: An Update of the 2011 ACCF/AHA/SCAI Guideline for Percutaneous Coronary Intervention, 2011 ACCF/AHA Guideline for Coronary Artery Bypass Graft Surgery, 2012 ACC/AHA/ACP/AATS/PCNA/SCAI/STS Guideline for the Diagnosis and Management of Patients With Stable Ischemic Heart Disease, 2013 ACCF/AHA Guideline for the Management of ST-Elevation Myocardial Infarction, 2014 AHA/ACC Guideline for the Management of Patients With Non-ST-Elevation Acute Coronary Syndromes, and 2014 ACC/AHA Guideline on Perioperative Cardiovascular Evaluation and Management of Patients Undergoing Noncardiac Surgery. Circulation 134 (10):e123-155. doi:10.1161/cir.0000000000000404

23. Valgimigli M, Bueno H, Byrne RA, Collet JP, Costa F, Jeppsson A, Jüni P, Kastrati A, Kolh P, Mauri L, Montalescot G, Neumann FJ, Petricevic M, Roffi M, Steg PG, Windecker S, Zamorano JL, Levine GN (2018) 2017 ESC focused update on dual antiplatelet therapy in coronary artery disease developed in collaboration with EACTS: The Task Force for dual antiplatelet therapy in coronary artery disease of the European Society of Cardiology (ESC) and of the European Association for Cardio-Thoracic Surgery (EACTS). Eur Heart J 39 (3):213-260. doi:10.1093/eurheartj/ehx419

24. Palmerini T, Benedetto U, Bacchi-Reggiani L, Della Riva D, Biondi-Zoccai G, Feres F, Abizaid A, Hong MK, Kim BK, Jang Y, Kim HS, Park KW, Genereux P, Bhatt DL, Orlandi C, De Servi S, Petrou M, Rapezzi C, Stone GW (2015) Mortality in patients treated with extended duration dual antiplatelet therapy after drugeluting stent implantation: a pairwise and Bayesian network meta-analysis of randomised trials. Lancet 385 (9985):2371-2382. doi:10.1016/s0140-6736(15)60263-x

25. Taniwaki M, Radu MD, Zaugg S, Amabile N, Garcia-Garcia HM, Yamaji K, Jørgensen E, Kelbæk H, Pilgrim T, Caussin C, Zanchin T, Veugeois A, Abildgaard U, Jüni P, Cook S, Koskinas KC, Windecker S, 
Räber L (2016) Mechanisms of Very Late Drug-Eluting Stent Thrombosis Assessed by Optical Coherence Tomography. Circulation 133 (7):650-660. doi:10.1161/circulationaha.115.019071

\section{Figures}

\section{ACS patients $(n=61)$}

From September 2020 and January 2021

\section{Ineligible ( $\mathbf{n}=25)$}

UPF-SES was implanted with OCT

$$
(\mathbf{n}=\mathbf{3 6})
$$

\section{Lost to follow-up \\ $(\mathbf{n}=\mathbf{5})$}

\section{Patients who underwent follow-up OCT $(\mathbf{n}=\mathbf{3 1})$}

Figure 1

Study Flow Chart Sixty-one patients presenting with acute coronary syndrome were assessed for eligibility in our institution between September 2020 and January 2021. Thirty-five patients underwent percutaneous coronary intervention using optical coherence tomography (OCT) and ultra-thin strut polymer-free sirolimus eluting stent (UPF-SES) were implanted. Finally, a total of 31 patients underwent a 3-month follow-up OCT examination. 


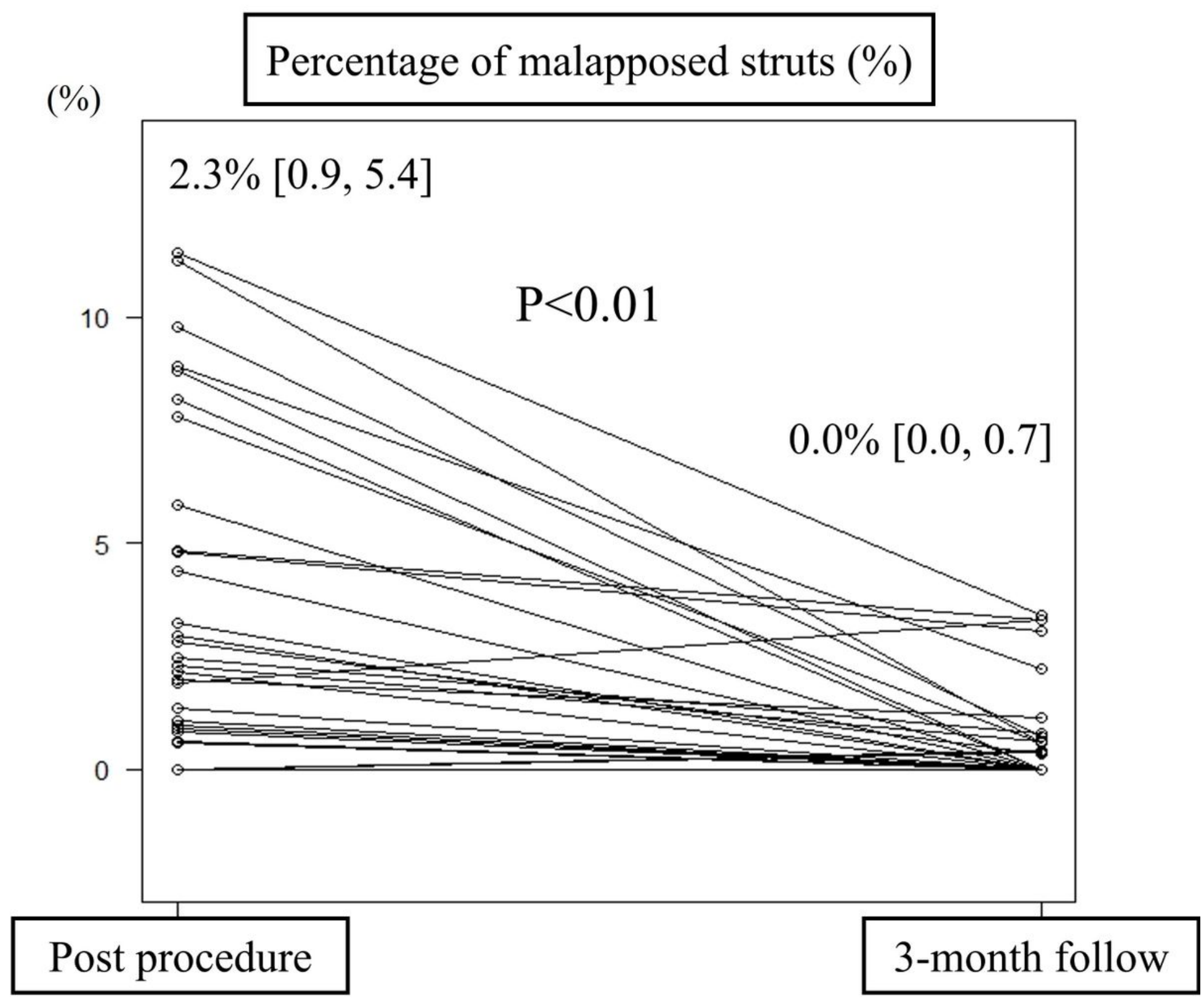

Figure 2

Individual Serial Changes in the Percentage of Malapposed Struts The percentage of malapposed struts significantly decreased during the 3 -month follow-up period $(p<0.01)$. 


\section{Post-procedural OCT images}

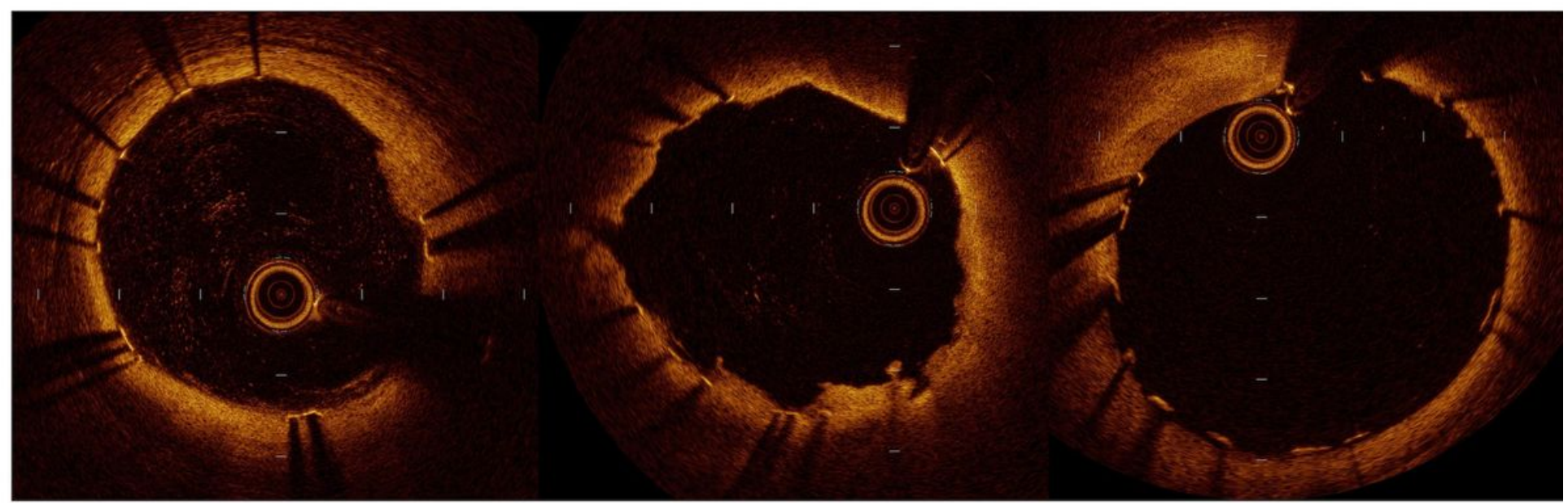

Distal site

Culprit site

Proximal site
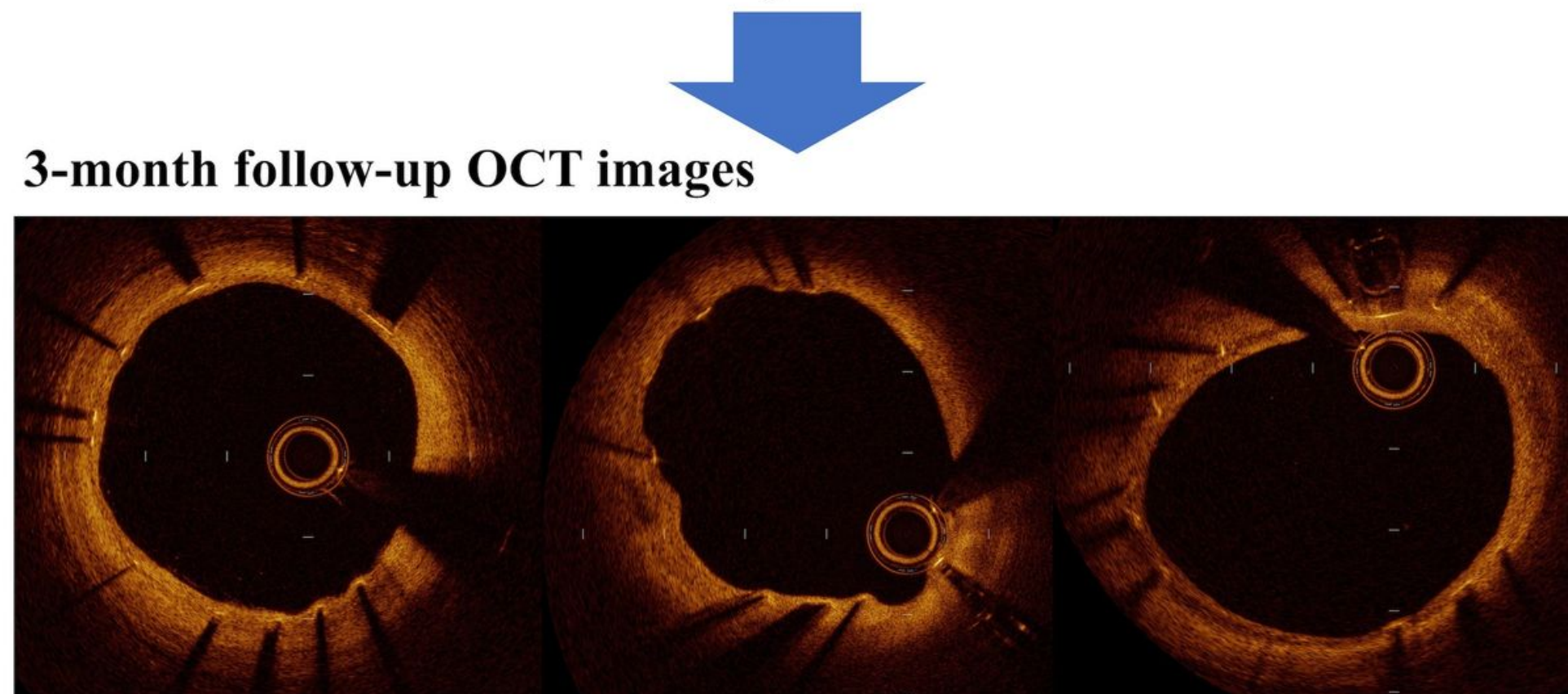

Distal site

Culprit site

Proximal site

Figure 3

Representative Serial OCT Images of the Struts and Neointimal Coverage over 3 months Ultra-thin strut polymer-free stent $(4.0 \mathrm{~mm} \times 24 \mathrm{~mm})$ was implanted in the patient. The left panel shows the distal site, middle panel the culprit site, and right panel the proximal site. All stent struts at those sites were covered by the neointima over 3 months. 